\title{
Fate of trace metals in anaerobic digestion biotechnologies
}

\author{
Fermoso, F. G. ${ }^{1}$; van Hullebusch, E. D. ${ }^{2}$; Guibaud, G. ${ }^{3}$; Collins, G. ${ }^{4,5}$; \\ Svensson, B. H. ${ }^{6}$; Carliell-Marquet, C. ${ }^{7}$; Vink, J.P.M. ${ }^{8}$; Esposito, G. ${ }^{9}$; Frunzo, \\ L. ${ }^{10}$
}

\begin{abstract}
A challenging, and largely uncharted, area of research in the field of anaerobic digestion science and technology is in understanding the roles of trace metals in enabling biogas production. This is a major knowledge gap and a multifaceted problem involving metal chemistry; physical interactions of metal and solids; microbiology; and technology optimization. Moreover, the fate of trace metals, and the chemical speciation and transport of trace metals in environments often agricultural lands receiving discharge waters from anaerobic digestion processes - is completely unknown but simultaneously represents challenges for environmental protection and opportunities to close process loops in anaerobic biotechnologies.
\end{abstract}

\footnotetext{
Affiliation

1. Instituto de la Grasa - C.S.I.C., Avd. Padre Garcia Tejero 4, 41012, Sevilla, Spain.

2. Université Paris-Est, Laboratoire Géomatériaux et Environnement (EA 4508), UPEM, 77454 Marne-la-Vallée, France.

3. University of Limoges Groupement de Recherche, Eau, Sol, Environnement, Faculté des Sciences et Techniques, 123 Av. Albert Thomas, 87060 Limoges, France.

4. Microbial Ecophysiology and EcoEngineering Laboratory, School of Natural Sciences, National University of Ireland Galway, University Road, Galway, Ireland.

5. School of Engineering, University of Glasgow, Rankine Building, Oakfield Avenue, Glasgow, G12 8LT, United Kingdom.

6. Linköping University. Dept Thematic Studies, Water and Environment, SE-581 83 Linköping, Sweden.

7. School of Civil Engineering, College of Engineering and Physical Sciences, University of Birmingham, B15 2TT Birmingham, United Kingdom.

8. Deltares foundation, Princetonlaan 6,3508 AL Utrecht, Netherlands.

9. Department of Civil and Mechanical Engineering, University of Cassino and the Southern Lazio, Via Di Biasio, 43, 03043 Cassino (FR), Italy.

10. Department of Mathematics and Applications Renato Caccioppoli, University of Naples Federico II, via Claudio 21, 80125 Naples, Italy.
} 


\section{Introduction}

Anaerobic digestion (AD) is an attractive bioenergy [1] and wastewater treatment technology $[2,3]$. The advantages of $\mathrm{AD}$ for waste treatment include: production of a useable fuel (biogas/methane); possibility of high organic loading; reduced carbon footprint; and suitability for integration into a wide variety of process configurations and scales [2, 4]. AD is increasingly applied world-wide; in 2011, 8,760 anaerobic bioreactors were reported in Europe, most of which were used to produce renewable energy from organic feedstock $[5,6]$, itself a limited resource. Internationally, the research effort to maximize biogas yield has increased ten-fold over the past decade [7, 8]. Still, a critical research question remains open: How does trace metal availability limit biogas production yield and how can this limitation be engineered out of the system? To answer this question with confidence, in such a complex matrix of substrates, microorganisms and chemical products, requires spanning fundamental molecular sciences to engineering applications; only then will the underpinning science be coupled successfully to engineering-led systems, benefitting end-users and producing more renewable energy.

Both the beneficial, and inhibitory or toxic effects of trace metals (TM) in anaerobic treatment processes have long been an interesting topic for researchers. Chalcogens - which include the trace elements selenium (Se), tellurium (Te) and radioactive polonium (Po) - although not metals, are included in the term TM in this chapter. The roles of TM in anaerobic processes are significant. Anaerobic fermentation and microbial growth is dependent on the availability and/or optimal supply of nutrients. Free metal ion availability is an important parameter that should be considered [9]. The requirements of various methanogens for iron $(\mathrm{Fe})$, nickel $(\mathrm{Ni})$, cobalt $(\mathrm{Co})$, molybdenum (Mo), selenium (Se) and tungsten $(\mathrm{W})$ have already been reported $[10$, 11]. Furthermore, the effects of TM such as Fe, Ni, Co, $\mathrm{Zn}$, Mo and $\mathrm{Cu}$ on anaerobic treatment of various types of industrial effluents have also been investigated in detail [12]. On the other hand, TM requirements of agricultural biogas systems operated with solid organic matter, such as energy crops, animal excreta, crop residues and the organic fraction of municipal solid wastes (OFMSW), are seldom reported in the literature, despite the exponentially-increased interest in biogas production from renewable sources [13].

Since industrial wastewaters and sludges contain elevated amounts of TM, most of the research activity has obviously been directed towards investigating the inhibitory and toxic effects of these elements on anaerobic wastewater treatment bioprocesses. During anaerobic conversion of energy crops, animal excreta, crop residues, OFMSW or any other type of organic wastes (e.g. food wastes) to biogasmethane, the availability, or lack, of TM, such as Fe, Co, Ni, Zn, Mo, W and Se, plays a significant role in maintaining stable and efficient conversion processes. Recently, it has been shown that food waste appears deficient in some TM, such as $\mathrm{Co}$ and $\mathrm{Se}$, required by the anaerobic digestion process when operating at high ammonia concentrations $[14,15]$. Such findings have major implications for successful and expanded application of AD biotechnology.

The area of TM bioavailability in AD systems calls for studies from several perspectives. Thus, efforts from a multitude of research fields are needed and the 
area is, by necessity, interdisciplinary. TM research draws on: physics e.g. rheology, diffusion, adsorption; organic, inorganic, physical and analytical chemistry; microbial physiology, genetics and biotechnology (laboratory-, pilot- and full-scale systems); agronomy and forestry biofertilization, among others. This chapter presents current research on five areas covering the fate and roles of TM in anaerobic biotechnologies: TM speciation and bioavailability in $\mathrm{AD}$ environments; TM microbiology and microbial ecology; biotechnology; fate of TM in the environment; and mathematical modelling.

\section{Trace metals speciation, fractioning and bioavailability}

The total metal concentration, the conditions during digestion such as $\mathrm{pH}$ and redox potential, and the reaction kinetics of chemical processes occurring in bioreactor liquid phase (i.e. trace elements reduction, precipitation or complexation) and solid phases (i.e. trace elements sorption) play key roles influencing the chemical speciation of $\mathrm{TM}$ in $\mathrm{AD}$ bioreactors. For instance, increasing $\mathrm{pH}$ decreases solubility of cationic metals in the matrix. The precipitation of metals by sulfide ( $\mathrm{S}^{2-}$ ), carbonate $\left(\mathrm{CO}_{3}{ }^{2-}\right)$ and phosphate $\left(\mathrm{PO}_{4}^{3-}\right)$, and their deposition in the bioreactor sludges/biofilms, plays an important role in nutrients, and TM, turnover [12, 16$18]$.

For instance, the presence of sulfide in biogas reactors affects the availability of TM needed for growth and metabolic activities of the microorganisms involved in AD. The solubility constants for complexes between most of the essential TM and sulfides are low and may lead to reduced bioavailability for these compounds [19]. High sulfide content in AD bioreactors may, therefore, result in suboptimal biogas production [20] and lead to a shift of micronutrients away from mobile forms toward more stable, and less reactive and bioavailable forms during $\mathrm{AD}$ [21]. However, due to its high corrosive properties, hydrogen sulfide affects biogas plant equipment and downstream biogas utilization devices, e.g. pipes and motors for converting the biogas to electricity and heat. Therefore, Fe may be dosed to biogas reactors to precipitate the sulfide formed and to avoid high concentration of hydrogen sulfide in the biogas $[18,20,22]$ leading to a complete change of sulfur turnover in $\mathrm{AD}$ reactors (Figure 1) and also to a significant change of macro and micronutrient speciation. There is a strong interaction of added $\mathrm{Fe}$ and the micronutrients in the matrix: micronutrients may react with the Fe-sulfide releasing $\mathrm{Fe}^{2+}$. The resulting $\mathrm{Fe}^{2+}$ may form precipitates as phosphates $\left(\mathrm{Fe}_{3}\left(\mathrm{PO}_{4}\right)_{2}\right)$ or carbonates $\left(\mathrm{FeCO}_{3}\right)[18]$. Consequently, bioreactors have a considerable ability to sequester $\mathrm{Fe}^{2+}$-ions in the sludge. Simultaneously, nonalkali metals $\left(e . g . \mathrm{Ca}^{2+}, \mathrm{Mg}^{2+}\right)$ form soluble ion pairs with a number of anions: $\mathrm{HCO}_{3}{ }^{-}, \mathrm{CO}_{3}{ }^{2-}, \mathrm{OH}^{-}, \mathrm{SO}_{4}{ }^{2-}, \mathrm{S}^{2-}[17]$. 


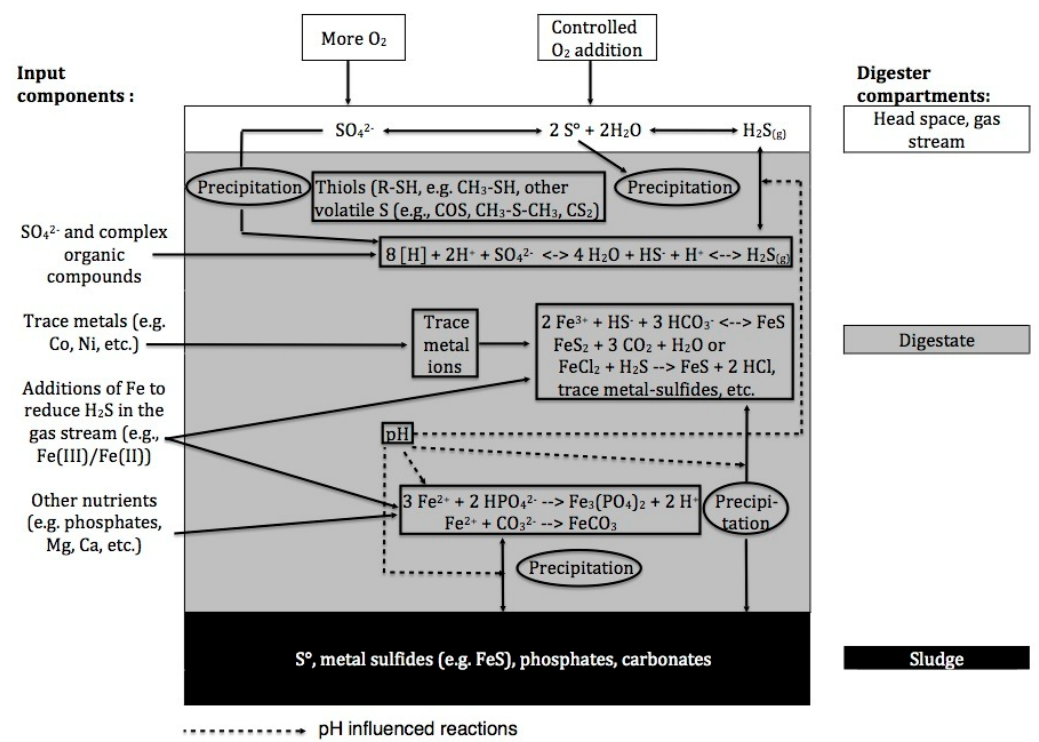

Figure 1. Sulfur turnover in biogas bioreactors and its influence on TM and nutrients speciation [modified from 17].

Furthermore, TM can interact with organic substances present in bioreactor, such as microbial cell wall (e.g. [23]), Extracellular Polymeric Substances (EPS) (e.g. [24]), Soluble Microbial Products (SMP) (e.g. [25]), organic substrates (e.g. yeast extract, [26]), organic sulfur compounds (e.g. organic thiol compounds ( $\left.\left.\mathrm{RS}^{-}\right),[22]\right)$, synthetic complexing agents, such as EDTA (e.g. $[27,28])$ or organic acids (e.g. [25]). The main interactions between organic substances and TM occur due to the presence ionisable functional groups, such as carboxylic, phosphoric, amino, and hydroxylic groups [29]. Molecular-level characterization of dissolved organic matter in biogas bioreactors digesting different types of substrate by electrospray ionization Fourier transform ion cyclotron resonance mass spectrometry (ESI-FTICR-MS) revealed that S-containing dissolved organic compounds including thiols may contribute up to $30 \%$ of dissolved organic molecules [30]. In addition, Li et al. [31] demonstrated that during anaerobic digestion chemical changes of dissolved organic matter during anaerobic digestion of dewatered sewage sludge using PARAllel FACtor analysis for decomposing fluorescence excitation emission matrices (EEM-PARAFAC) and two-dimensional FTIR correlation spectroscopy. Li et al. [31] showed that fluorescence intensities of the components relating to tyrosine-like, tryptophan-like and humic-like groups increased in Dissolved Organic Matter, implying that these groups were reluctant to biodegrade and could participate in TM complexation. It has been recently shown that trace elements may be significantly complexed by organic compounds harbouring thiol functional groups [22].

Complexation reactions (in the liquid phase or the solid phase) play an important role in bioreactors making a particular TM either more or less bioavailable. The 
level of soluble TM in the presence of $\mathrm{CO}_{3}{ }^{2-}$ and $\mathrm{S}^{2-}$ may be increased by a factor of up to $10^{4}$ by organic complexation, avoiding precipitation as carbonates or sulfides [19]. However, up to now little quantitative information has been published regarding the contribution of organic substances in TM complexation and its effect on TM bioavailability.

Bioreactors where sulfide concentration is high and where iron dosing is needed to prevent corrosion problems constitute good models for studying TM bioavailability. The chemical forms and potential bioavailability of trace elements could be examined by sequential extraction, acid volatile sulfide extraction (AVS) and simultaneously extracted metals analysis [32]. Furthermore, knowing the importance of sulfur in trace elements bioavailability and speciation, sulfur speciation in solid phase could be examined by X-ray absorption near edge structure spectroscopy at Sulfur K-edge [18, 20, 22, 33]. For instance, Shakeri Yekta et al. [22] assessed major chemical reactions and chemical forms contributing to solubility and speciation of $\mathrm{Fe}, \mathrm{Co}$, and $\mathrm{Ni}$ during anaerobic digestion of sulfur (S)rich stillage in semi-continuous stirred tank biogas reactors (SCSTR). A particular focus was given to the study of the influence of reduced inorganic and organic $\mathrm{S}$ species on kinetics and thermodynamics of the metals and their partitioning between aqueous and solid phases were investigated. Solid phase $\mathrm{S}$ speciation was determined by use of X-ray absorption near-edge spectroscopy at S K-edge. By combining the quantitative sulfur speciation information with a thermodynamic equilibrium model including precipitation/dissolution of metal-sulfides and complex formation reactions involving inorganic sulfide and organic thiols as the major reactions controlling solubility and chemical speciation of the TM, Shakeri Yekta et al. [22] demonstrated that the solubility and speciation of supplemented Fe were controlled by precipitation of $\mathrm{FeS}_{(\mathrm{s})}$ and formation of the aqueous complexes of Fe-sulfide and Fe-thiol. The relatively high solubility of Co ( $\sim 20 \%$ of total Co content) was attributed to the formation of compounds other than Co-sulfide and Co-thiol, presumably of microbial origin. Ni had lower solubility than Co and its speciation was regulated by interactions with $\mathrm{FeS}_{(\mathrm{s})}$ (e.g. co-precipitation, adsorption, and ion substitution) in addition to precipitation/dissolution of discrete $\mathrm{NiS}_{(\mathrm{s})}$ phase and formation of aqueous Ni-sulfide complexes. Such analytical approaches could be successfully implemented provided that a good knowledge of the key players involved in TM speciation is achieved. Furthermore, development of analytical tools allowing to reach the TM speciation dynamics as defined by Pinheiro et al. [34] under conditions of bulk depletion is needed. In such particular conditions [19], the speciation and bioavailability of TM must be considered at two different time scales: (i) the time scale of the bio-uptake flux, as determined by diffusion of the bioactive free metal, dissociation of the bioinactive complex species, and the internalization rate; and (ii) the time scale of depletion of the bulk medium. Donnan Membrane Technique (DMT) [35] as well as Diffusive Gradient in Thin film (DGT) [36] could provide such type of information provided that the analytical approach allows to work at very low TM concentrations levels as well as in anaerobic conditions. Also a link between TM bioavailability and the microbial community response should be better understood [37]. 


\section{Trace metal microbiology and microbial ecology}

Development and optimisation of AD requires better knowledge of the mechanisms occurring on a microscale, which should in turn be linked to the macroscale system performance and behaviour [38]. Despite this, the relationships between the dynamic behavior of microbial communities and environmental parameters in AD have hardly been studied [1,39]. Indeed, there is a pressing need for more and better information on the biology, rates and limitations of microbially-mediated processes during $\mathrm{AD}$. Thus, the weakest component of many $\mathrm{AD}$ bioreactor operations is the available information on the structure, dynamics and functions of the microbial community underpinning digestion and biogas production. This is certainly valid for the interactions between TM and the microorganisms.

Several studies have reported on the effects of TM deprivation, or supplementation, on the performance of anaerobic bioreactors and on the temporal dynamics of microbial populations. The acidification of methanol-fed bioreactors induced by Co deprivation from the influent was investigated by Fermoso et al. [40] by coupling analysis of bioreactor performance indicators and the microbial ecology, and activity, of the bioreactor sludge. Under Co-limiting conditions in methanol-fed bioreactors, methanogenic activity of bioreactor sludge granules on methanol gradually decreased, leading to methanol accumulation and bioreactor acidi-fication due to acetogenic thermodynamic out-competition of methylothrophic methanogenesis. Methylotrophic, and acetoclastic, methanogenic activity was found to be lost within 10 days of reactor operation, coinciding with the disappearance of a Methanosarcina population. Using fluorescence in-situ hybridisations (FISH), along with activity assays, Fermoso et al. [40] concluded that reduced methanogenic activity on methanol, and shifts in population dynamics, could be used as accurate parameters to predict bioreactor acidification under Colimiting conditions.

Zn-deprivation, and subsequent Zn-supplementation, was investigated in Upflow Anaerobic Sludge Bed (UASB) bioreactors by Fermoso et al. [41]. Significantly reduced methanogenic activity on methanol was observed under Zn-limited conditions, which could not be restored by resuming the continuous supply of the deprived metal. Moreover, FISH analysis indicated that the growth of Methanosarcina colonies was irreversibly inhibited by Zn-deprivation. Similarly, Gustavsson et al. [20] found that microbial community structure in bioreactors treating sulfur-rich feedstocks varied with the availability of $\mathrm{Ni}$ and $\mathrm{Co}$. Acetateutilizing Methanosarcinales were dominant during periods of stable process performance, i.e. with $\mathrm{Co}$ and $\mathrm{Ni}$ supply, but the abundance of hydrogenotrophic Methanomicrobiales increased significantly, along with volatile fatty acids (VFA) concentrations, under $\mathrm{Co}$ or Ni deficiency. The increase was more pronounced at Co limitation. Such studies demonstrate the potential to improve bioreactor performance by managing microbial communities and by supplementation with TM.

However, the impact of TM, and of changing TM concentrations in bioreactors, on biofilm development; microbial community structure; population dynamics; and the metabolism of individual trophic groups and the meta-community (i.e. the microbial 
community, as a 'meta-organism', incorporating metabolites as well as cells) is still largely unknown. This is a reflection of the inherent, technical challenges facing microbiologists in understanding the reactions and interactions of complex, mixedspecies biofilms, as well as the slow shift from viewing dynamic, engineered systems as 'black boxes' without consideration for the active microbial communities present. Nonetheless, it is also related to the obvious focus on reactions and processes converting organic molecules at the expense of understanding the importance and roles of, and requirements for, TM in anaerobic bioreactors.

Verstraete et al. [42] review the challenge of managing microbial resources in open and complex, mixed-species communities in the context of dynamic populations and chemical micro-environments. They defined the concept of 'Microbial Resource Management' (MRM), which is analogous to Human Resource Management, and the requirement to handle questions such as 'who is there', 'who is doing what with whom' and 'how can one adjust, control and/or steer these mixed cultures and communities'? Just as with the grand challenges of MRM, as outlined by Verstraete et al. [42], such as controlling greenhouse gas emissions from natural environments, or managing the human gut microbiome, similarly provocative questions should be considered as to how the availability of TM impacts the management of microbial communities in anaerobic biotechnologies. The use of $\mathrm{TM}$ to manage microbial community structure in the AD context is given support by the study of Feng et al. [37] demonstrating microbial shifts in response to varying concentrations and combinations of TM. For example, they showed that a change of the TM profiles resulted in the occurrence of different strains on Methanoculleus. The abundance of these strains varied in relation to concentrations of nickel/molybdenum/boron and/or selenium/tungsten applied in the biogas reactors investigated. Information on the regulation of TM-responsive gene transcription in microbial species in $\mathrm{AD}$ biofilms is obviously also important in understanding and managing the impact of TM, and in optimizing TM application strategies in bioreactors. Kazakov et al. [43], for example, recently described a new family of tungstate-responsive transcriptional regulators in sulfate-reducing bacteria, which are - thermodynamically - important components of the microbial community in many $\mathrm{AD}$ bioreactors, where they can compete for substrates and energy with methanogens. However, the impact of responsive regulatory systems on the wider community should also be explored in order to assess the outlook for the performance of whole bioreactors.

Systems biology allows an holistic understanding of the meta-community. Systems biology determines the DNA sequences; the collectively-transcribed RNA; the translated proteins; and the metabolites resulting from cellular processes. Metagenomics, metatranscriptomics, metaproteomics and metabolomics data can lead from the (i) functional potential of the ecosystem, to (ii) indications of microbial activity, through (iii) identification of active metabolic pathways and to (iv) identification of the intermediate- and end-products of cellular processes, respectively. However, none - or even pairs - of the 'omics approaches alone can provide comprehensive information on ecosystem function.

Siggins et al. [44] reviewed advances in metaproteomics and the need to combine this with metagenomics and metabolomics. The study of collective expression of all 
proteins by the individuals in a microbial community, i.e. metaproteomics, can provide insights into microbial functionality. For example, the expression of proteins associated with methanogenic pathways under various states of TM deprivation and supplementation can provide valuable insights to the importance of specific TM for reactions under in-situ conditions. However, only collectively can these techniques capture the functional interactions occurring in an ecosystem and track down characteristics that could not be accessed by the study of isolated components.

Successful systems biology strategies will likely be based on the application of polyomics - genomics, transcriptomics, metabolomics and fluxomics - and will benefit also from innovative integrations with techniques and approaches, such as microfluidic cell counting and sorting, and ecological modeling. The objective of systems microbiology in mixed-species communities should be to facilitate prediction of ecosystem characteristics, which, in the context of TM strategies in $\mathrm{AD}$, would support process optimisation with reference to TM concentrations and availability, and the development of new applications. To maximise the impact of systems biology datasets with reference to TM in AD processes, the response and regulation of microbial uptake mechanisms in relation to the speciation of the TM complexes should be focused. Moreover, the impact that the regulatory response of individuals has on the global function of the entire community - and the "metaorganism' in bioreactors - should be investigated, since inter-dependencies underpin the functioning of diverse AD microbial communities.

In addition, ecosystems biology models have potential for predicting, and hence supporting optimisation and management, of microbial community function in AD systems. Probabilistic models are required, which will incorporate the stochasticity necessary to reflect the environmental conditions in bioreactors that can be used to identify functionally-important groups of microbial individuals in AD systems, and the impact of TM on microorganisms.

Since, ultimately, the goal is to control microbial communities for optimum rates of conversion and bioreactor performance, reliable means are also required of diagnosing problems at the level of the microbial community. This represents a reasonably straightforward and logical requirement once the important, and relevant, pathways and reactions affected by TM availability have been identified. For example, the phylogenetic markers (such as the 16S rRNA gene) or functional genes associated with the populations or processes affected by TM availability can be monitored by quantitative Polymerase Chain Reaction (qPCR) assays. Indeed, gene expression analysis by reverse-transcription quantitative PCR (RT-qPCR), which allows quantification of RNA (transcripts) rather than genes, has been a key enabling technology of the post-genome era. A comprehensive review of the origins and the future potential of qPCR is available from van Guilder et al. [45]. In the context, however, of quantifying DNA or RNA targets from complex microbial communities, and to develop reliable diagnostic tools to support optimized bioreactor operation, including, for example, TM dosing strategies, several additional considerations may apply. Nucleic acids extractions techniques may require optimisation [46] and PCR assays with environmental and bioengineered samples are often particularly challenging [47]. The sensitivity and specificity of qPCR assays, and of the Nucleic Acids diagnostic Tests (NATs) developed thereof, 
are critical considerations [48]. The cost and reproducibility, as well as the ease-ofuse and robustness, of NATs for different samples is also important for optimal use of quantitative, molecular diagnostics tools to monitor the metals-related 'health' of functional groups in anaerobic biotechnologies.

An opportunity to advance this field will be in integrating innovative experimental approaches to measure TM speciation and bioavailability, with community-level microbial ecology and ecophysiology. Furthermore, it is well-known that microbes are able to implement specific strategies to cope with metal deficiency (i.e. micronutrient starvation) or excess (i.e. intrinsic toxicity) by altering the chemical speciation of metals in their surrounding environment. When metals are available in low concentrations or in less bioavailable forms (e.g. under sulfidic condition and extensive metal-sulfide precipitation), microbes are able to excrete strong metalbinding organic compounds to facilitate the uptake of essential metals. These extracellular organic compounds encompass strong metal binding properties and in many cases may result in enhanced solubility of metal-bearing minerals [49]. A well-studied example is microbial $\mathrm{Fe}$ acquisition by excretion of Fe-chelating siderophores and further uptake by cognate receptors [50]. Similar processes are believed to be responsible for the increase in $\mathrm{Co}$ and $\mathrm{Ni}$ solubility and bio-uptake under sulfidic conditions of the natural environments [51, 52]. Some microorganisms have developed metal efflux mechanisms, which pumps excess intracellular metals out of the cell as a strategy against metal toxicity when exposed to high concentrations of metals [53]. Although this topic is well studied in disciplines such as organic chemistry, biogeochemistry and medicine, only a few studies have targeted the effect of microbial stress response under metal deficiency/excess on metal speciation in biogas processes. The various uptake mechanism among the microorganisms active during $\mathrm{AD}$ should therefore be targeted as a part of the ecophysiological investigations referred to above aiming at the effects of the TM on the microbial community structure.

\section{Biotechnology}

The operational performance of an anaerobic bioreactor dictates the commercial viability of $\mathrm{AD}$ installations. A healthy anaerobic bioreactor converts organic waste material to biogas at the appropriate rate to accommodate the required organic loading and to produce biogas- and hence bioenergy - at a profitable level. It also demonstrates operational stability and resilience and produces digestate that complies with certification limits for farmland application. Figure 2 shows the different aspects of anaerobic digestion that must work cooperatively to yield methane from organic feedstock. The bioavailability of both macro- and microelements (including TM) will have an impact on the microbial community and prevailing biochemical pathways in an anaerobic bioreactor, and hence ultimately on the methane produced by that bioreactor. 


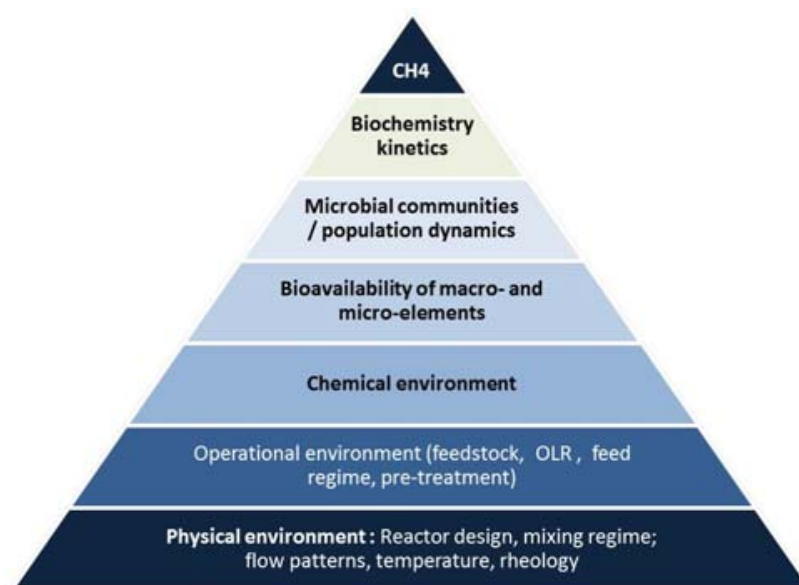

Figure 2. Depiction of how the physical, operational, chemical and microbiological aspects of anaerobic digestion combine to produce methane from organic waste.

A poorly performing anaerobic bioreactor might be prone to accumulation of volatile fatty acids leading to souring and shutdown; or prolonged periods of foaming that make mixing and gas collection difficult and negatively affects the quality of the digestate end-product. For engineers it is important to understand the relationship between TM bioavailability and bioreactor design and operation in order to judge whether TM supplementation would be beneficial to biogas yield. When an anaerobic bioreactor is treating a defined industrial waste or effluent it is fairly straightforward to determine which $\mathrm{TM}$ are lacking in the feed; supplementation of the missing elements almost always results in improved biogas yield and operational stability [20,54], including an interesting example of abatement of foaming in a slaughterhouse waste bioreactor supplemented with cobalt (Jörgen Ejlertsson, personal communication).

What is more challenging is to decide whether an anaerobic bioreactor with a full complement of TM in reasonable quantities might in fact be TM deficient; perhaps due to the metals speciated in such a way that they are not bioavailable within the required timescale of digestion. Ishaq et al. [55] showed that sewage sludge bioreactor s with no obvious TM deficiencies (but recorded as under-performing with respect to electricity production) responded positively to TM supplementation, in particular cobalt supplementation, with increases in the rate of conversion of acetate to methane being recorded in the range of $9 \%$ to $50 \%$ in Biochemical Methane Potential (BMP) assays.

Required TM supplements are hence determined by what is not present in the feed and/or what is not bioavailable in the feed. The microbial species and hence dominant biochemical pathways in that bioreactor will also determine which TM supplements are most appropriate. For example, Fermoso et al. [40] showed that UASB bioreactors treating methanol were strongly dependent on cobalt supplementation to maintain high biogas yield and bioreactor stability, whereas UASB bioreactors treating an acetate-based waste were less responsive to cobalt supplementation. So a TM supplement that suits one bioreactor will not necessarily 
be as effective at another bioreactor site. This leads to the question of how the potential benefits of TM supplements can be evaluated at laboratory-scale? BMP batch assays are commonly used to evaluate the effect of TM supplements on the rate of conversion of feedstock to methane. The test is rapid (5 to 10 days depending on the feedstock) and relatively inexpensive to perform but it evaluates primarily the immediate response of the existing microbial community to TM supplements. The BMP test does not give an indication of how the community might evolve as the TM composition of the bioreactor changes.

TM may have synergistic or even antagonistic effects depending on their relative concentrations in a supplement. It is important to understand which TM is critically limiting to be able to develop appropriate bespoke supplements for individual bioreactors if required to optimize biogas yield or stabilize a bioreactor [15]. TM supplementation in $\mathrm{AD}$ systems is a compromise between achieving the maximal biological activity of the biomass present in the reactor, while minimizing the costs of the supplied metal and the TM losses into the environment. The boundary conditions to keep a stable reactor operation vary between nutrient deficiencies due to lack of essential TM and toxicity due to their excess [56]. The TM addition strategy, for example, whether TM are added as metal chelates that are unlikely to precipitate or metal salts that are likely to precipitate, affects the TM losses and hence costs to achieve the optimal TM concentration inside the AD system.

In completely mixed anaerobic reactors, precipitation of TM confers little advantage in terms of TM retention in the bioreactor; hence dosing of TM as soluble (chelated) complexes could be advantageous to improve their availability for rapid microbial uptake. Conversely, anaerobic reactors that decouple the biomass retention time from the hydraulic retention time, such as UASB and SBR (Sequencing Batch Reactor), are likely to benefit from being dosed with TM salts so that the metals will precipitate and accumulate within the biomass sludge fraction, from which they can be assimilated more slowly by the microorganisms as they are required $[54,57]$. This is more cost effective than dosing chelated TM that are washed out of the reactor in a matter of hours, even if there is a trade-off in bioavailability.

Depending on the type of substrate to be digested; bioreactor type; and the digestion procedure (mono or co-digestion) employed; TM requirements of anaerobic bioreactors could also theoretically be provided through mixing various feedstocks, such as by co-digesting with sewage sludge, OFMSW or animal excreta, or externally by using chemical additives $[58,59]$. Agricultural biogas plants operating with energy crops, such as maize and grass as mono-substrates, can sometimes face suboptimal bioreactor performance without any obvious reason at first glance, but the VFA concentrations range between 3 and $5 \mathrm{~kg} \mathrm{~m}^{-3}$ (recently studied in Germany and Austria by Hinken et al., Pobeheim et al. and Lindorfer et al. [60-62]). Then, the lack or unavailability of micro-nutrients (i.e. trace metals) should be the first reason to be questioned [13].

Anaerobic bioreactors rarely exist in isolation and are usually part of bigger installations with other operations upstream that will have an impact on the bioreactor, for example, sewage sludge anaerobic bioreactors treat the sludge generated through primary and secondary sewage treatment; agricultural anaerobic bioreactors treat manure generated by upstream processes such as milk production; 
and industrial anaerobic bioreactors are vulnerable to upstream changes in the factory processes that then affect the wastewater composition. Any changes upstream can affect both the composition and bioavailability of TM in the anaerobic bioreactor feedstock and hence have unintended consequences on the methane yield of that bioreactor. A study by Carliell-Marquet et al. [63] showed that introducing iron dosing for chemical phosphorus removal at a sewage treatment works changed the way trace metals were fractionated. Iron shifted to less easily extractable fractions, indicating a potential decrease in bioavailability, whereas copper and zinc moved down the fractionation profiles to be recovered more readily, indicating a potential shift towards being more bioavailable. A key point for AD engineers is that upstream process decisions can also impact on TM composition in anaerobic bioreactor feedstock and hence also on methane yield.

\section{Fate of trace metals in the environment}

During AD of substrates such as sediments and organic materials, TM species are formed under reducing conditions. Microbial organic matter synthesis effectively reduces redox potential, and produces a range of organic TM complexes and stable inorganic precipitates. After anaerobic digestion, TM are released into the environment as soil or compost via different routes of entry (i.e. suspended / dissolved in effluents or in solid as excess biomass). Once outside the reducing conditions of $\mathrm{AD}$ fermenters, waste materials face aerobic conditions that may lead to chemical and physical oxidation and changes in availability of TM. Since legislation has become aware of the potential environmental risks involved (i.e., elevated exposure of (toxic) TM to humans, cattle and ecosystems), the application on land and other forms of re-use is in many EU countries restricted. Nevertheless, the possibilities to include bioavailability in site-specific risk assessment have been included in European guidelines as second-tier methods. This may offer opportunities to derive low-risk conditions and enable safe re-use of materials.

\section{Risk assessment of substrates on land}

Many authors have reported on oxidation mechanisms that occur when anaerobic materials become aerobic [64-67]. Redox sequences have been discussed extensively in terms of thermodynamic pathways, and there is sufficient agreement on the (bio)chemical mechanisms that occur upon reduction and oxidation. Numerical models were developed specifically to address the quantitative effects of redox sequence and TM speciation (e.g., [68,69]) in terms of resulting pore water concentrations and emission of TM to the environment.

Despite this general agreement on chemical and biochemical mechanisms, the final result of oxidation seldom follows generic rules and often remains uncertain. The final endpoint is the sum of intermediate reactions that occur during oxidation and is largely dictated by the solid phase composition of the substrate and its ability to 
counteract adverse effects [70-73]. In Table 1, some of these reactions are summarized.

Table 1. Oxidation reactions and their effects.

\begin{tabular}{ll}
\hline Reaction & Physical or chemical effect \\
\hline Organic metabolism & Eh $\downarrow ; \mathrm{pH} \downarrow ; \mathrm{pCO}_{2} \uparrow ;$ \\
$\mathrm{CH}_{2} \mathrm{O}+\mathrm{O}_{2}>\mathrm{CO}_{2}+\mathrm{H}_{2} \mathrm{O}$ & Possible acidification; Release of \\
$\mathrm{CO}_{2}+\mathrm{H}_{2} \mathrm{O}>\mathrm{HCO}_{3}{ }^{-}+\mathrm{H}^{+}$ & sorbed TM; Increase of DOC. \\
$\mathrm{Sulfide} /$ pyrite oxidation & $\mathrm{pH} \downarrow ;$ \\
$\mathrm{FeS}(\mathrm{s})+9 / 4 \mathrm{O}_{2}+1.5 \mathrm{H}_{2} \mathrm{O}>\mathrm{FeOOH}(\mathrm{s})+2 \mathrm{H}^{+}$ & Release of S-associated TM; \\
$+\mathrm{SO}_{4}{ }^{2-}$ & Sorption of TM to iron(hydr)oxides; \\
& Possible eutrophication. \\
Nitrification & pH $\downarrow ;$ Possible eutrophication. \\
$\mathrm{NH}_{4}{ }^{+}+2 \mathrm{O}_{2}>\mathrm{NO}_{3}{ }^{-}+2 \mathrm{H}^{+}+\mathrm{H}_{2} \mathrm{O}$ & \\
& \\
\hline
\end{tabular}

Figure 3 shows an example of the oxidation of anaerobic sediment sludge that was brought on land. This case shows that a drop in $\mathrm{pH}$ occurred of almost two units. This is most probably the result of oxidation of relatively large quantities of sulfides, given the increase of $\mathrm{SO}_{4}{ }^{2-}$. Sulfide-associated $\mathrm{TM}$ are released as a consequence. The effect may be superimposed by competition of $\mathrm{H}^{+}$ions with TM for organic and inorganic sorption sites.

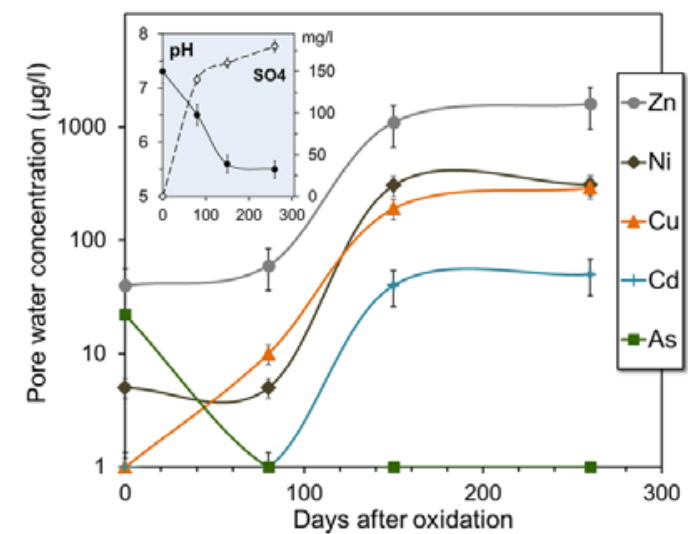

Figure 3. Pore water concentrations of some TM after dumping of anaerobic sludge on land. Oxidation of stable sulfide precipitates releases TM and sulfate. When insufficiently buffered, acidification may give rise to significant release of TM to pore water and possible emission to the surrounding environment.

Xiang et al. [67] used these chemical characteristics to actively release TM from anaerobically digested sludge. The inoculation of indigenous Fe-oxidizing bacteria and the addition of $\mathrm{FeSO}_{4}$ accelerated the solubilisation of $\mathrm{Cr}, \mathrm{Cu}, \mathrm{Zn}, \mathrm{Ni}$ and $\mathrm{Pb}$ at 
a $\mathrm{pH}$ that dropped to 2.5 . Removal efficiencies were obtained that ranged from $16 \%$ $(\mathrm{Pb})$ to $92 \%(\mathrm{Cu})$. It was reported that the residual TM content in the leached sludge was acceptable for unrestricted use for agriculture.

However, release of $\mathrm{H}^{+}$not necessarily has to lead to actual acidification. A substrate or the receiving environment may be capable of buffering the input of protons either by sorption (e.g., by organic components) or reaction with alkaline products (e.g., $\mathrm{CaCO}_{3}$ ). In cases of abundant iron, the formation of reactive ironoxyhydroxides may drastically increase sorption capacity of the substrate for TM and prevent their release. Using these properties, either intrinsic or by additions, may prove to be a cost-effective and environmentally safe option when compared to active removal processes.

\section{Risks assessment in aquatic environments}

For TM, environmental quality standards for sediments and surface waters have been developed to protect the ecosystem from adverse effects. These quality standards are generic, which means that they apply to all surface waters. The importance of explicitly considering bioavailability in the development of water and sediment quality criteria for TM has been recognized for some time [74]. Criteria that incorporate this concept were considered for regulatory implementation for some time [75-77].

Biotic ligand models (BLM) were developed to incorporate local bioavailability in risk assessment procedures. The conceptual framework for the BLM is an adaptation of the gill surface interaction model, originally proposed by Pagenkopf $[78,79]$ and more recently utilized by many others (e.g., [80-84]), and the free ion activity model of toxicity, extensively reviewed by e.g., $[85,86]$. The general framework is illustrated in Figure 4. The model is based on the hypothesis that toxicity (expressed as No-effect concentration; NOEC) is not simply related to total aqueous TM concentration but that both TM-ligand complexation and TM interaction with competing cations at the site of action of toxicity need to be considered $[78,87,88]$. Mortality occurs when the concentration of TM bound to the biotic ligand exceeds a threshold concentration. The BLM simply replaces the fish gill as the site of action with a more generally characterized site, the biotic ligand. The reason for this replacement is to emphasize that this model should be applicable to other aquatic organisms, like crustaceans, for which the site of action is not readily accessible to direct measurement. It is likely that these principles apply to any organism for which the site of action is directly in contact with the external aqueous environment. 


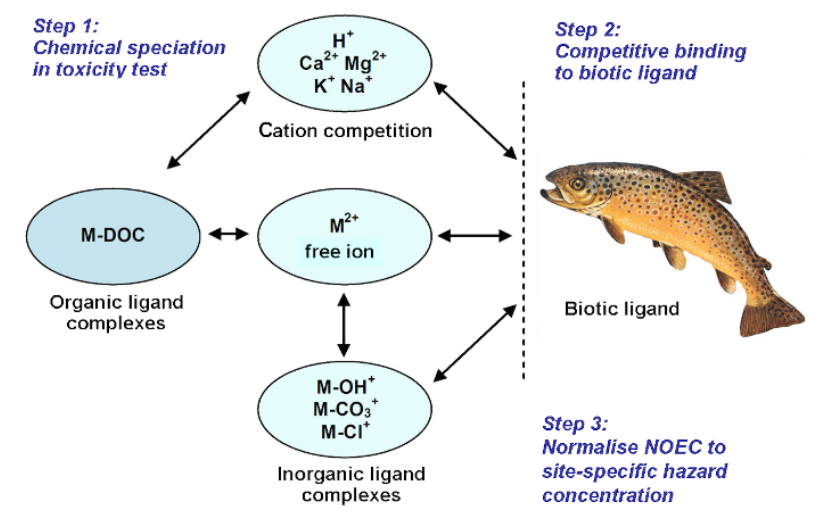

Figure 4. The biotic ligand model for TM includes calculation of chemical speciation, binding to biota and a normalisation procedure to calculate site-specific quality standards.

The role of TM complexation is critical because formation of organic and inorganic metal complexes renders a significant fraction of the total TM nonbioavailable. In fact, this modeling framework defines bioavailability of TM. Dissolved TM exists in solution partially as free TM ion [89, 90]. This species is hypothesized to be the bioavailable species in more simplified versions of the free ion activity model of toxicity. The rest of the TM exists as non-bioavailable TM complexes that result from reactions of the TM with organic and inorganic ligands. Biotic ligand models were developed and validated for $\mathrm{Cu}, \mathrm{Ni}$ and $\mathrm{Zn}$. Efforts to develop BLMs for other TM (such as Co (e.g., [83]) and Cd (e.g., [91]) are undertaken and tested for uncertainty [92]. For $\mathrm{Cd}$, a bioavailability correction factor based on water hardness has been suggested (e.g., [87]).

Recently, Verschoor et al. [93] performed a geographical and temporal analysis of TM in surface waters, and concluded that "sensitive" and "robust" waters occur, based on their physic-chemical composition. By incorporating chemical speciation of TM in the assessment of ecotoxicological risks for aquatic species, site-specific variations are made visible that remain undetected when checked with generic quality standards. A long history of experiments has provided sufficient evidence for the importance of water chemistry on the adverse effects (toxicity) of heavy metals and other compounds to aquatic organisms.

\section{Mathematical modelling}

During recent decades, several researchers published a series of mathematical models to simulate the AD process [94-100]. These models are focused on different aspects of $\mathrm{AD}$ and have shown good performances in terms of simulation accuracy. The different approaches proposed by the different models, however, make it very difficult to either compare the results of, or to integrate, two or more models. 
In 2002, the International Water Association (IWA) Task Group for Mathematical Modelling of Anaerobic Digestion Processes developed a comprehensive mathematical model known as ADM1-Anaerobic Digestion Model no. 1 [101], which was based on the collective knowledge of modelling and simulation of AD systems.

The aim of the ADM1 approach is not to provide an overall model but to supply a unified basis for AD modelling; indeed the first version of ADM1 neglects certain processes involved in $\mathrm{AD}$, such as sulfate reduction, acetate oxidation, homoacetogenesis, solids precipitation and inhibition due to sulfide, nitrate, longchain fatty acids (LCFAs), and weak acids and bases [102].

Some of the neglected aspects have since been studied and modelled; for instance, two ADM1 extensions were published in 2003 concerning, respectively, sulfate reduction [103] and $\mathrm{CaCO}_{3}$ precipitation [104]. A further extension to remove the ADM1 discrepancies in both carbon and nitrogen balances was later published [105]. Lubken et al. [106] proposed a first modified version of the ADM1, able to take into account the co-digestion of different substrates. More precisely, in the model of Lubken et al. [106], the energy production by co-digesting cattle manure and energy crops was evaluated. Esposito et al. [107] modified the ADM1 to include the possibility to model the disintegration of two different input substrates. Their proposed model considers first-order kinetics for sewage sludge disintegration and surface-based kinetics to model OFMSW disintegration. This model has also since been upgraded [108] to simulate the effect of LCFA production in $\mathrm{pH}$ prediction and to include the possibility of separating each product of the disintegration process (i.e. carbohydrates, proteins and lipids) into two fractions, i.e. a readily biodegradable fraction and a slowly biodegradable fraction.

Nevertheless there are several studies that demonstrated the significant effects of TM, and their speciation, in AD. Shakeri Yetka et al. [18] have suggested to combine available bio-uptake theories such as free ion activity and biotic ligand models with the chemical speciation modelling and their further incorporation into mechanistic models describing overall anaerobic digestion process such as ADM1. However, to the best of our knowledge, there are no dynamic mathematical models that could take into account these phenomena. In addition, the ADM1 model does not yet consider the phylogenetic complexity of microbial communities underpinning the $\mathrm{AD}$ process, or the dynamic nature of microbial community structure in response to changing environmental conditions. Therefore, a new theoretical model, based on the ADM1 approach, is needed to simulate the effect of $\mathrm{TM}$ and their speciation in anaerobic digestion systems.

This mathematical model should include the following characteristics:

1. Ordinary differential equations able to describe the speciation of the TM present in the simulated biological system. In particular these equations should provide the dynamic concentrations of each TM species. Proper description of the TM chemical speciation in a system where diverse organic molecules are present in high concentrations requires identification and inclusion of main metal-binding ligands in particular dissolved organic matter and their stability constants.

2. Differential mass balance equations for substrates, products and bacterial groups involved in the process. These equations include biochemical 
reactions of substrate conversion and microbial growth and decay kinetics, considering the effects of TM speciation (Table 2). In particular the kinetic equations reported in Table 2 consider the mechanisms of microbial uptake of TM (including their inhibitory and nutritious effects) which is the bridge for connecting TM speciation to microbial growth, decay, and maintenance activities.

3. A module aimed at the determination of the redox potential that is needed to model the TM speciation.

4. Ideally, the incorporation of data on the diversity and abundance, as well as responses to TM concentrations and availability, of the microbial populations in $\mathrm{AD}$ bioreactors.

5. Differential parabolic equations capable to model the diffusivity phenomena in the biofilm in case of attached growth reactors. These equations will consider the different diffusivity constant of each TM species.

6. A module to simulate the fate of trace metals in the environment and to assess the risks in soil and aquatic systems.

Table 2. Inhibition forms, readapted for TM concentrations. $K_{I}=$ inhibition parameter; $r_{j}=r$ ate for process $j ; S_{j}=$ substrate for process $j ; M_{I}=$ inhibitor concentration; $X_{j}=$ biomass for process $j ; K_{m}=$ Monod maximum specific uptake rate; $K_{s}=$ half saturation value; $Y=$ yield of biomass on substrate; $K_{q}$ $=$ first order decay rate; $\mathrm{M}_{\mathrm{LL}}$ and $\mathrm{M}_{\mathrm{UL}}=$ lower and upper limits where the group of organisms is $50 \%$ inhibited, respectively.

\begin{tabular}{cc}
\hline Description & Equation \\
\hline Uncompetitive inhibition & $\rho_{j}=\frac{K_{m} X S}{K_{S}+S\left(1+\frac{K_{I}}{M_{I}}\right)}$ \\
Competitive inhibition & $\rho_{j}=\frac{K_{m} X S}{K_{S}\left(1+\frac{M_{I}}{K_{I}}\right)+S}$ \\
Reduction in yield \\
$\begin{array}{c}\text { Increased biological } \\
\text { decay rate } \\
\text { Empirical upper and lower } \\
\text { inhibition }\end{array}$ & $Y=f\left(M_{I}\right)$ \\
\end{tabular}

\section{Outlook}

A challenging area of $\mathrm{AD}$ research remains largely unchartered with respect to understanding the role of TM in enhancing biogas production. Since performance dictates the commercial viability of $\mathrm{AD}$, more attention to managing the $\mathrm{TM}$ needs of $\mathrm{AD}$ processes will improve the overall prospects for the technology. This major 
knowledge gap and scientific challenge is a multifaceted problem involving TM chemistry, physical interactions of TM and solids, microbiology, microbial ecology and technology optimization. Moreover, the fate of TMs, and the chemical speciation, transport and ecological impact of TMs in environments - often agricultural lands - receiving discharge waters from $\mathrm{AD}$ is largely unknown or at least uncertain. This means that the fate of TM in AD biotechnologies has an inherent importance, which should be explored jointly by multi-disciplinary efforts to provide relevant, and reliable, information and tools for industry and to develop the role and use of TM to enhance biogas production in anaerobic biotechnologies.

\section{Acknowledgments}

The authors acknowledge funding within the framework of the COST Action 1302 ('European Network on Ecological Roles of Trace Metals in Anaerobic Biotechnologies'). GC is supported by a European Research Council Starting Grant ('3C-BIOTECH; No. 261330).

\section{References}

1. Appels, L., J. Lauwers, J. Degrve, L. Helsen, B. Lievens, K. Willems, J. Van Impe, and R. Dewil, Anaerobic digestion in global bio-energy production: Potential and research challenges. Renewable and Sustainable Energy Reviews, 2011. 15(9): p. 4295-4301.

2. Lettinga, G., The anaerobic treatment approach towards a more sustainable and robust environmental protection. 2005. p. 1-11.

3. Verstraete, W., P. Van de Caveye, and V. Diamantis, Maximum use of resources present in domestic "used water". Bioresource Technology, 2009. 100(23): p. 5537-5545.

4. Zeeman, G., K. Kujawa, T. de Mes, L. Hernandez, M. de Graaff, L. AbuGhunmi, A. Mels, B. Meulman, H. Temmink, C. Buisman, J. van Lier, and G. Lettinga, Anaerobic treatment as a core technology for energy, nutrients and water recovery from source-separated domestic waste(water). 2008. p. 1207-1212.

5. Nichols, C.E., Overview of anaerobic digestion technologies in Europe. BioCycle, 2004. 45(1): p. 47-48+50-53.

6. Cameron, I., Biogas market comes on strong. Diesel and Gas Turbine Worldwide, 2007. 39(5): p. 10-13.

7. Chong, S., T.K. Sen, A. Kayaalp, and H.M. Ang, The performance enhancements of upflow anaerobic sludge blanket (UASB) reactors for domestic sludge treatment - A State-of-the-art review. Water Research, 2012. 46(11): p. 3434-3470.

8. Chanakya, H.N. and S. Malayil, Anaerobic digestion for bioenergy from agro-residues and other solid wastes - An overview of science, technology 
and sustainability. Journal of the Indian Institute of Science, 2012. 92(1): p. 111-143.

9. Zandvoort, M.M., E.D. van Hullebusch, F.G. Fermoso, and P. Lens, Trace metals in anaerobic granular sludge reactors: Bioavailability and dosing strategies. Engineering in life sciences, 2006. 6(3): p. 293-301.

10. Glass, J.B. and V.J. Orphan, Trace metal requirements for microbial enzymes involved in the production and consumption of methane and nitrous oxide. Frontiers in Microbiology, 2012. 3(FEB).

11. Worm, P., F.G. Fermoso, P.N.L. Lens, and C.M. Plugge, Decreased activity of a propionate degrading community in a UASB reactor fed with synthetic medium without molybdenum, tungsten and selenium. Enzyme and Microbial Technology, 2009. 45(2): p. 139-145.

12. Zandvoort, M.H., E.D. van Hullebusch, J. Gieteling, and P.N.L. Lens, Granular sludge in full-scale anaerobic bioreactors: Trace element content and deficiencies. Enzyme and Microbial Technology, 2006. 39(2): p. 337-346.

13. Demirel, B. and P. Scherer, Trace element requirements of agricultural biogas digesters during biological conversion of renewable biomass to methane. Biomass and Bioenergy, 2011. 35(3): p. 992-998.

14. Facchin, V., C. Cavinato, P. Pavan, and D. Bolzonella, Batch and continuous mesophilic anaerobic digestion of food waste: Effect of trace elements supplementation. Chemical Engineering Transactions, 2013. 32: p. $457-462$.

15. Banks, C.J., Y. Zhang, Y. Jiang, and S. Heaven, Trace element requirements for stable food waste digestion at elevated ammonia concentrations. Bioresource Technology, 2012. 104: p. 127-135.

16. van Hullebusch, E.D., M.H. Zandvoort, and P.N.L. Lens, Metal immobilisation by biofilms: Mechanisms and analytical tools. Reviews in Environmental Science and Biotechnology, 2003. 2(1): p. 9-33.

17. Möller, K. and T. Müller, Effects of anaerobic digestion on digestate nutrient availability and crop growth: A review. Engineering in Life Sciences, 2012. 12(3): p. 242-257.

18. Shakeri Yekta, S., B.H. Svensson, A. Björn, and S. U., Thermodynamic modeling of iron and trace metal solubility and specia-tion under sulfidic and ferruginous conditions in full scale continuous stirred tank biogas reactors. Applied Geochemistry, 2014. In press.

19. Jansen, S., Speciation and bioavailability of cobalt and nickel in anaerobic wastewater treatment, in Leerstoelgroep Fysische Chemie en Kolloidkunde. 2004, Wageningen University

20. Gustavsson, J., S. Shakeri Yekta, C. Sundberg, A. Karlsson, J. Ejlertsson, U. Skyllberg, and B.H. Svensson, Bioavailability of cobalt and nickel during anaerobic digestion of sulfur-rich stillage for biogas formation. Applied Energy, 2013. 112: p. 473-477.

21. Zandvoort, M.H., E.D. van Hullebusch, J. Gieteling, G. Lettinga, and P.N.L. Lens, Effect of Sulfur Source on the Performance and Metal 
Retention of Methanol-Fed UASB Reactors. Biotechnol. Prog., 2005. 21(3): p. 839-850.

22. Shakeri Yekta, S., A. Lindmark, U. Skyllberg, T. Danielsson, and B.H. Svensson, Importance of reduced sulfur for the equilibrium chemistry and kinetics of $\mathrm{Fe}(\mathrm{II}), \mathrm{Co}(\mathrm{II})$ and $\mathrm{Ni}(\mathrm{II})$ supplemented to semi-continuous stirred tank biogas reactors fed with stillage. Journal of Hazardous Materials, 2014. 269: p. 83-88.

23. Kenney, J.P.L. and J.B. Fein, Cell wall reactivity of acidophilic and alkaliphilic bacteria determined by potentiometric titrations and cd adsorption experiments. Environmental Science and Technology, 2011. 45(10): p. 4446-4452.

24. d'Abzac, P., F. Bordas, E.D. van Hullebusch, P.N.L. Lens, and G. Guibaud, Effects of extraction procedures on metal binding properties of extracellular polymeric substances (EPS) from anaerobic granular sludges. Colloids and Surfaces B: Biointerfaces, 2010. 80(2): p. 161-168.

25. Aquino, S.F. and D.C. Stuckey, Bioavailability and toxicity of metal nutrients during anaerobic digestion. Journal of Environmental Engineering, 2007. 133(1): p. 28-35.

26. Gonzalez-Gil, G., S. Jansen, M. Zandvoort, and H.P. van Leeuwen, Effect of yeast extract on speciation and bioavailability of nickel and cobalt in anaerobic bioreactors. Biotechnology and Bioengineering, 2003. 82(2): p. 134-142.

27. Bartacek, J., F.G. Fermoso, A.M. Baldo-Urrutia, E.D. van Hullebusch, and P.N.L. Lens, Cobalt toxicity in anaerobic granular sludge: Influence of chemical speciation. Journal of Industrial Microbiology and Biotechnology, 2008. 35(11): p. 1465-1474.

28. Fermoso, F.G., J. Bartacek, L.C. Chung, and P. Lens, Supplementation of cobalt to UASB reactors by pulse dosing: CoCl2 versus CoEDTA2- pulses. Biochemical Engineering Journal, 2008. 42(2): p. 111-119.

29. d'Abzac, P., F. Bordas, E. Joussein, E.D. van Hullebusch, P.N.L. Lens, and G. Guibaud, Metal binding properties of extracellular polymeric substances extracted from anaerobic granular sludges. Environmental Science and Pollution Research, 2013. 20(7): p. 4509-4519.

30. Shakeri Yekta, S., J. Gustavsson, B.H. Svensson, and U. Skyllberg, Sulfur K-edge XANES and acid volatile sulfide analyses of changes in chemical speciation of $S$ and $\mathrm{Fe}$ during sequential extraction of trace metals in anoxic sludge from biogas reactors. Talanta, 2012. 89: p. 470-477.

31. Li, X., X. Dai, J. Takahashi, N. Li, J. Jin, L. Dai, and B. Dong, New insight into chemical changes of dissolved organic matter during anaerobic digestion of dewatered sewage sludge using EEM-PARAFAC and twodimensional FTIR correlation spectroscopy. Bioresource Technology, 2014. 159: p. 412-420.

32. Van der Veen, A., F.G. Fermoso, and P. Lens, Bonding form analysis of metals and sulfur fractionation in methanol-grown anaerobic granular sludge Engineering in Life Science 2007. 7 (5): p. 480-489. 
33. van Hullebusch, E.D., S. Rossano, F. Farges, M. Lenz, J. Labanowski, P. Lagarde, A.-M. Flank, and P.N.L. Lens. Sulfur K-edge XANES spectroscopy as a tool for understanding sulfur chemical state in anaerobic granular biofilms. in 14th International Confer-ence on X-ray Absorption Fine Structure (XAFS14). 2009. Camerino, Italy.

34. Pinheiro, J.P., J. Galceran, and H.P. Van Leeuwen, Metal Speciation Dynamics and Bioavailability: Bulk Depletion Effects. Environmental Science and Technology, 2004. 38(8): p. 2397-2405.

35. Temminghoff, E.J.M., A.C.C. Plette, R. Van Eck, and W.H. Van Riemsdijk, Determination of the chemical speciation of trace metals in aqueous systems by the Wageningen Donnan membrane technique. Analytica Chimica Acta, 2000. 417(2): p. 149-157.

36. Davison, W. and H. Zhang, In situ speciation measurements of trace components in natural waters using thin-film gels. Nature, 1994. 367(6463): p. 546.

37. Feng, X.M., A. Karlsson, B.H. Svensson, and S. Bertilsson, Impact of trace element addition on biogas production from food industrial waste Linking process to microbial communities. FEMS Microbiology Ecology, 2010. 74(1): p. 226-240.

38. Rittmann, B.E., R. Krajmalnik-Brown, and R.U. Halden, Pre-genomic, genomic and post-genomic study of microbial communities involved in bioenergy. Nature Reviews Microbiology, 2008. 6(8): p. 604-612.

39. Tomei, M.C., C.M. Braguglia, G. Cento, and G. Mininni, Modeling of Anaerobic digestion of sludge. Critical Reviews in Environmental Science and Technology, 2009. 39(12): p. 1003-1051.

40. Fermoso, F.G., G. Collins, J. Bartacek, V. O'Flaherty, and P. Lens, Acidification of methanol-fed anaerobic granular sludge bioreactors by cobalt deprivation: Induction and microbial community dynamics. Biotechnol Bioeng, 2008. 99(1): p. 49-58.

41. Fermoso, F.G., G. Collins, J. Bartacek, and P.N.L. Lens, Zinc deprivation of methanol fed anaerobic granular sludge bioreactors. Journal of Industrial Microbiology \& Biotechnology, 2008. 35(6): p. 543-557.

42. Verstraete, W., L. Wittebolle, K. Heylen, B. Vanparys, P. de Vos, T. van de Wiele, and N. Boon, Microbial Resource Management: The road to go for environmental biotechnology. Engineering in Life Sciences, 2007. 7(2): p. 117-126.

43. Kazakov, A.E., L. Rajeev, E.G. Luning, G.M. Zane, K. Siddartha, D.A. Rodionov, I. Dubchak, A.P. Arkin, J.D. Wall, A. Mukhopadhyay, and P.S. Novichkov, New family of tungstate-responsive transcriptional regulators in sulfate-reducing bacteria. Journal of Bacteriology, 2013. 195(19): p. 4466-4475.

44. Siggins, A., E. Gunnigle, and F. Abram, Exploring mixed microbial community functioning: Recent advances in metaproteomics. FEMS Microbiology Ecology, 2012. 80(2): p. 265-280. 
45. VanGuilder, H.D., K.E. Vrana, and W.M. Freeman, Twenty-five years of quantitative PCR for gene expression analysis. BioTechniques, 2008. 44(5): p. 619-626.

46. Carrigg, C., O. Rice, S. Kavanagh, G. Collins, and V. O'Flaherty, DNA extraction method affects microbial community profiles from soils and sediment. Applied Microbiology and Biotechnology, 2007. 77(4): p. 955964.

47. Smith, C.J. and A.M. Osborn, Advantages and limitations of quantitative PCR (Q-PCR)-based approaches in microbial ecology. FEMS Microbiology Ecology, 2009. 67(1): p. 6-20.

48. Myint, M.S., Y.J. Johnson, N.L. Tablante, and R.A. Heckert, The effect of pre-enrichment protocol on the sensitivity and specificity of PCR for detection of naturally contaminated Salmonella in raw poultry compared to conventional culture. Food Microbiology, 2006. 23(6): p. 599-604.

49. Banfield, J.F., W.W. Barker, S.A. Welch, and A. Taunton, Biological impact on mineral dissolution: Application of the lichen model to understanding mineral weathering in the rhizosphere. Proceedings of the National Academy of Sciences of the United States of America, 1999. 96(7): p. 3404-3411.

50. Krewulak, K.D. and H.J. Vogel, Structural biology of bacterial iron uptake. Biochimica et Biophysica Acta - Biomembranes, 2008. 1778(9): p. 1781-1804.

51. Saito, M.A., J.W. Moffett, S.W. Chisholm, and J.B. Waterbury, Cobalt limitation and uptake in Prochlorococcus. Journal Limnology and Oceanography, 2002. 47(6): p. 1629-1636.

52. Waldron, K.J. and N.J. Robinson, How do bacterial cells ensure that metalloproteins get the correct metal? Nature Reviews Microbiology, 2009. 7(1): p. 25-35.

53. Rodrigue, A., G. Effantin, and M.A. Mandrand-Berthelot, Identification of rcnA (yohM), a nickel and cobalt resistance gene in Escherichia coli. Journal of Bacteriology, 2005. 187(8): p. 2912-2916.

54. Fermoso, F.G., J. Bartacek, R. Manzano, H.P. van Leeuwen, and P.N. Lens, Dosing of anaerobic granular sludge bioreactors with cobalt: impact of cobalt retention on methanogenic activity. Bioresour Technol, 2010. 101(24): p. 9429-37.

55. Ishaq, F., J. Bridgeman, and C.M. Carliell-Marquet, Site energy performance as an indicator for trace element deficiency in full-scale digesters, in 13th World Congress on Anaerobic Digestion (IWA Specialist Conference). 2013: Santiago de Compostela, Spain.

56. Fermoso, F.G., J. Bartacek, S. Jansen, and P.N. Lens, Metal supplementation to UASB bioreactors: from cell-metal interactions to fullscale application. Sci Total Environ, 2009. 407(12): p. 3652-67.

57. Jansen, S., G. Gonzalez-Gil, and H.P. van Leeuwen, The impact of Co and $\mathrm{Ni}$ speciation on methanogenesis in sulfidic media - Biouptake versus 
metal dissolution. Enzyme and Microbial Technology, 2007. 40(4): p. 823830 .

58. Nges, I.A. and L. Björnsson, High methane yields and stable operation during anaerobic digestion of nutrient-supplemented energy crop mixtures. Biomass and Bioenergy, 2012. 47: p. 62-70.

59. Nges, I.A., A. Björn, and L. Björnsson, Stable operation during pilot-scale anaerobic digestion of nutrient-supplemented maize/sugar beet silage. Bioresource Technology, 2012. 118: p. 445-454.

60. Pobeheim, H., B. Munk, H. Lindorfer, and G.M. Guebitz, Impact of nickel and cobalt on biogas production and process stability during semicontinuous anaerobic fermentation of a model substrate for maize silage. Water Research, 2011. 45(2): p. 781-787.

61. Lindorfer, H., D. Ramhold, and B. Frauz, Nutrient and trace element supply in anaerobic digestion plants and effect of trace element application. Water Science and Technology, 2012. 66(9): p. 1923-1929.

62. Hinken, L., I. Urban, E. Haun, D. Weichgrebe, and K.H. Rosenwinkel, The valuation of malnutrition in the mono-digestion of maize silage by anaerobic batch tests. 2008. p. 1453-1459.

63. Carliell-Marquet, C., J. Smith, I. Oikonomidis, and A. Wheatley, Inorganic profiles of chemical phosphorus removal sludge. Proceedings of the Institution of Civil Engineers: Water Management, 2010. 163(2): p. 65-77.

64. Holmes, J., Fate of incorporated metals during mackinawite oxidation in sea water. Applied Geochemistry, 1999. 14(3): p. 277-281.

65. Mayer, T.D. and W.M. Jarrell, Phosphorus sorption during iron(II) oxidation in the presence of dissolved silica. Water Research, 2000. 34(16): p. 3949-3956.

66. Simpson, S.L., S.G. Apte, and G.E. Batley, Effect of short-term resuspension events on the oxidation of cadmium, lead, and zinc sulfide phases in anoxic estuarine sediments. Environmental Science and Technology, 2000. 34(21): p. 4533-4537.

67. Xiang, L., L.C. Chan, and J.W.C. Wong, Removal of heavy metals from anaerobically digested sewage sludge by isolated indigenous ironoxidizing bacteria. Chemosphere, 2000. 41(1-2): p. 283-287.

68. Vink, J.P.M. and J.C.L. Meeussen, BIOCHEM-ORCHESTRA: A tool for evaluating chemical speciation and ecotoxicological impacts of heavy metals on river flood plain systems. Environmental Pollution, 2007. 148(3): p. 833-841.

69. Christensen, J.B. and T.H. Christensen, Complexation of Cd, Ni, and Zn by DOC in polluted groundwater: A comparison of approaches using resin exchange, aquifer material sorption, and computer speciation models (WHAM and MINTEQA2). Environmental Science and Technology, 1999. 33(21): p. 3857-3863.

70. Di Toro, D.M., H.E. Allen, H.L. Bergman, J.S. Meyer, P.R. Paquin, and R.C. Santore, Biotic ligand model of the acute toxicity of metals. 1. 
Technical basis. Environmental Toxicology and Chemistry, 2001. 20(10): p. 2383-2396.

71. Lamers, L.P.M., H.B.M. Tomassen, and J.G.M. Roelofs, Sulfate-induced eutrophication and phytotoxicity in freshwater wetlands. Environmental Science and Technology, 1998. 32(2): p. 199-205.

72. Siegrist, H., I. Brunner, G. Koch, L.C. Phan, and C. Van Le, Reduction of biomass decay rate under anoxic and anaerobic conditions. 1999. p. 129137.

73. Vink, J.P.M., J. Harmsen, and H. Rijnaarts, Delayed immobilization of heavy metals in soils and sediments under reducing and anaerobic conditions; consequences for flooding and storage. Journal of Soils and Sediments, 2010. 10(8): p. 1633-1645.

74. Ankley, G.T., D.M. Di Toro, D.J. Hansen, and W.J. Berry, Technical basis and proposal for deriving sediment quality criteria for metals. Environmental Toxicology and Chemistry, 1996. 15(12): p. 2056-2066.

75. Bergman, H.L. and E.J. Dorward-King, Reassessment of metals criteria for aquatic life protection: priorities for research and implementation : proceedings of the Pellston Workshop on Reassessment of Metals Criteria for Aquatic Life Protection, 10-14 February 1996, Pensacola, Florida. 1997: SETAC Press.

76. Renner, R., Rethinking water quality standards for metals toxicity. Environmental Science and Technology, 1997. 31(10): p. 465A-468A.

77. EU, Directive 2008/105/EC OF THE European Parliament and of the Council of 16 December 2008 on environmental quality standards in the field of water policy, amending and subsequently repealing Council Directives 82/176/EEC, 83/513/EEC, 84/156/EEC, 84/491/EEC, 86/280/EEC and amending Directive 2000/60/EC of the European Parliament and of the Council. 2008. p. 14 pages.

78. Pagenkopf, G.K., Gill surface interaction model for trace-metal toxicity to fishes: Role of complexation, $p M$, and water hardness. Environmental Science and Technology, 1983. 17(6): p. 342-347.

79. Pagenkopf, G.K., R.C. Russo, and R.V. Thurston, Effect of complexation on toxicity of copper to fishes. J. Fish. Res. Board Canada, 1974. 31(4): p. 462-465.

80. Hollis, L., K. Burnison, and R.C. Playle, Does the age of metal-dissolved organic carbon complexes influence binding of metals to fish gills? Aquatic Toxicology, 1996. 35(3-4): p. 253-264.

81. Janes, N. and R.C. Playle, Modeling silver binding to gills of rainbow trout (Oncorhynchus mykiss). Environmental Toxicology and Chemistry, 1995. 14(11): p. 1847-1858.

82. Playle, R.C., Modelling metal interactions at fish gills. Science of the Total Environment, 1998. 219(2-3): p. 147-163.

83. Richards, J.G. and R.C. Playle, Cobalt binding to gills of rainbow trout (Oncorhynchus mykiss): An equilibrium model. Comparative 
Biochemistry and Physiology - C Pharmacology Toxicology and Endocrinology, 1998. 119(2): p. 185-197.

84. Wood, C.M., R.C. Playle, and C. Hogstrand, Physiology and modeling of mechanisms of silver uptake and toxicity in fish. Environmental Toxicology and Chemistry, 1999. 18(1): p. 71-83.

85. Morel, F., Principles of aquatic chemistry. 1983: J. Wiley.

86. Campbell, P.G., In Interactions between trace metals and aquatic organisms: A critique of the free-ion activity model, in Metal Speciation and Bioavailability in AquaticSystems, A. Tessier and D. Turner, Editors. 1995, John Wiley: New York, NY, USA. p. 45-102.

87. Meyer, J.S., A mechanistic explanation for the In(LC50) vs In(hardness) adjustment equation for metals. Environmental Science and Technology, 1999. 33(6): p. 908-912.

88. Paquin, P.R., D.M. Di Toro, R.C. Santore, D. Trivedi, and K.B. Wu, A Biotic Ligand Model of the Acute Toxicity of Metals: III. Application to Fish and Daphnia Exposure to Silver, in In Integrated Approach to Assessing the Bioavailability and Toxicity of Metals in Surface Waters and Sediments, U.E. EPA-822-E-99-001, Editor. 1999: Washington, DC. p. 359-3-102.

89. Vink, J.P.M., The origin of speciation: Trace metal kinetics over natural water/sediment interfaces and the consequences for bioaccumulation. Environmental Pollution, 2009. 157(2): p. 519-527.

90. Vink, J.P.M., Measurement of heavy metal speciation over redox gradients in natural water-sediment interfaces and implications for uptake by benthic organisms. Environmental Science and Technology, 2002. 36(23): p. 5130-5138.

91. Niyogi, S., R. Kent, and C.M. Wood, Effects of water chemistry variables on gill binding and acute toxicity of cadmium in rainbow trout (Oncorhynchus mykiss): A biotic ligand model (BLM) approach. Comparative Biochemistry and Physiology - C Toxicology and Pharmacology, 2008. 148(4): p. 305-314.

92. Vijver, M.G., A. De Koning, and W.J.G.M. Peijnenburg, Uncertainty of water type-specific hazardous copper concentrations derived with biotic ligand models. Environmental Toxicology and Chemistry, 2008. 27(11): p. 2311-2319.

93. Verschoor, A.J., J.P.M. Vink, G.R. De Snoo, and M.G. Vijver, Spatial and temporal variation of watertype-specific no-effect concentrations and risks of $\mathrm{Cu}, \mathrm{Ni}$, and $\mathrm{Zn}$. Environmental Science and Technology, 2011. 45(14): p. 6049-6056.

94. Hill, D. and C. Barth, A dynamic model for simulation of animal waste digestion. Journal (Water Pollution Control Federation), 1977: p. 21292143.

95. Kalyuzhnyi, S. and M. Davlyatshina, Batch anaerobic digestion of glucose and its mathematical modeling. I. Kinetic investigations. Bioresource Technology, 1997. 59(1): p. 73-80. 
96. Mosey, F., Mathematical modelling of the anaerobic digestion process: regulatory mechanisms for the formation of short-chain volatile acids from glucose. Water Science \& Technology, 1983. 15(8-9): p. 209-232.

97. Costello, D., P. Greenfield, and P.L. Lee, Dynamic modelling of a singlestage high-rate anaerobic reactor-I. Model derivation. Water Research, 1991. 25(7): p. 847-858.

98. Batstone, D., J. Keller, R. Newell, and M. Newland, Modelling anaerobic degradation of complex wastewater. I: model development. Bioresource Technology, 2000. 75(1): p. 67-74.

99. Angelidaki, I., L. Ellegaard, and B.K. Ahring, A mathematical model for dynamic simulation of anaerobic digestion of complex substrates: focusing on ammonia inhibition. Biotechnology and Bioengineering, 1993. 42(2): p. 159-166.

100. Vavilin, V., V. Vasiliev, A. Ponomarev, and S. Rytow, Simulation model 'methane'as a tool for effective biogas production during anaerobic conversion of complex organic matter. Bioresource Technology, 1994. 48(1): p. 1-8.

101. Batstone, D.J., J. Keller, I. Angelidaki, S.V. Kalyuzhnyi, S.G. Pavlostathis, A. Rozzi, W.T. Sanders, H. Siegrist, and V.A. Vavilin, The IWA Anaerobic Digestion Model No 1 (ADM1). Water Science and Technology, 2002. 45(10): p. 65-73.

102. Fuentes, M., N.J. Scenna, P.A. Aguirre, and M.C. Mussati, Application of two anaerobic digestion models to biofilm systems. Biochemical Engineering Journal, 2008. 38(2): p. 259-269.

103. Fedorovich, V., P. Lens, and S. Kalyuzhnyi, Extension of anaerobic digestion model no. 1 with processes of sulfate reduction. Applied Biochemistry and Biotechnology - Part A Enzyme Engineering and Biotechnology, 2003. 109(1-3): p. 33-45.

104. Batstone, D.J. and J. Keller, Industrial applications of the IWA anaerobic digestion model No. 1 (ADM1), in Water Science and Technology. 2003. p. 199-206.

105. Blumensaat, F. and J. Keller, Modelling of two-stage anaerobic digestion using the IWA Anaerobic Digestion Model No. 1 (ADM1). Water Research, 2005. 39(1): p. 171-183.

106. Lübken, M., M. Wichern, M. Schlattmann, A. Gronauer, and H. Horn, Modelling the energy balance of an anaerobic digester fed with cattle manure and renewable energy crops. Water Research, 2007. 41(18): p. 4085-4096.

107. Esposito, G., L. Frunzo, A. Panico, and G. d'Antonio, Mathematical modelling of disintegration-limited co-digestion of OFMSW and sewage sludge. Water Science and Technology, 2008. 58( 7): p. 1513-1519.

108. Esposito, G., L. Frunzo, A. Panico, and F. Pirozzi, Modelling the effect of the OLR and OFMSW particle size on the performances of an anaerobic co-digestion reactor. Process Biochemistry, 2011. 46(2): p. 557-565. 
